\title{
Achievements and Prospects of Advanced Pavement Materials Technologies
}

\author{
Zhanping You ${ }^{1, *(1)}$, Jian-long Zheng ${ }^{2}$ and Hainian Wang ${ }^{3}$ \\ 1 Department of Civil and Environmental Engineering, Michigan Technological University, 1400 Townsend \\ Drive, Houghton, MI 49931, USA \\ 2 School of Traffic and Transportation Engineering, Changsha University of Science and Technology (CSUST), \\ Changsha 410004, China; zjl@csust.edu.cn \\ 3 College of Transport Infrastructure, Chang'an University, South Erhuan Middle Section, Xi'an 710064, China; \\ wanghn@chd.edu.cn \\ * Correspondence: zyou@mtu.edu
}

Received: 8 September 2020; Accepted: 8 September 2020; Published: 2 November 2020

check for updates

Road transportation is a basic need for mobility and daily life. Currently, there are a number of challenges in dealing with distressed pavement and seeking new materials with sustainability in mind in pavement systems. Therefore, it is important for us to conduct further research in the following areas: (1) pavement structure, materials, and design; (2) pavement models as better solutions for pavement constructions; (3) pavement mechanics for improved understanding and mechanism analyses; (4) utilization of recycled materials for environmentally friendly solutions; (5) maintenance and rehabilitation for an extended life span of pavement; (6) intelligent construction for project management, energy conservation, and future constructions; and (7) innovative approaches to test and evaluate the performance of pavement materials. The purpose of this Special Issue "Achievements and Prospects of Advanced Pavement Materials Technologies" is to explore new research ideas for pavement materials as described above.

The Special Issue "Achievements and Prospects of Advanced Pavement Materials Technologies" is part of the journal Applied Sciences (ISSN 2076-3417). This Special Issue belongs to the section "Materials." This Special Issue contains 25 technical articles [1-25]. All of the 25 papers have been peer reviewed under the journal's rigorous review criteria. The collection includes invited papers from experts in international communities and articles that have been selected from the 2019 World Transport Convention (WTC) held in June 2019 in Beijing, the 4th International Conference on Transportation Infrastructure and Materials in Jinan, Shandong, China in 2019, and the 5th Chinese-European Workshop on Functional Pavements in 2019 in Changsha, China.

Modified asphalt binders and mixtures are the most important construction materials for pavement, and therefore they always attract research interest all over the world. Nearly half of the papers collected in this Special Issue are related to these topics. M. Hasan, Z. You, M. Satar, M. Warid, N. Kamaruddin, D. Ge, and R. Zhang evaluated the effects of Titanate coupling agent on the engineering properties of asphalt binders and mixtures incorporating LLDPE- $\mathrm{CaCO}_{3}$ pellets [8]. Another paper presents an investigation on a damage model of an eco-friendly basalt fiber-modified asphalt mixture under freeze-thaw cycles [18], authored by W. Wang, Y. Cheng, G. Ma, G. Tan, X. Sun, and S. Yang. Additionally, C. Zhang, H. Wang, Z. You, J. Gao, and M. Irfan investigated the performance of styrene-butadiene-styrene (SBS)-modified asphalt based on the different evaluation methods [22]. The micromechanism of the dispersion behavior of polymer-modified rejuvenators in aged asphalt materials is presented by M. Zhao, F. Shen, and Q. Ding. Studies on manufacturing modifiers are also included, such as preparation of polyacrylate hollow microspheres [4] and design of SBS-modified bitumen stabilizer powder based on the vulcanization mechanism [23]. 
Nanotechnology has been adopted by researchers to reinforce properties of asphalt binders and mixtures. J. Rafi, M. Kamal, N. Ahmad, M. Hafeez, M. Faizan ul Haq, S. Aamara Asif, F. Shabbir, and S. Bilal Ahmed Zaidi used carbon black nanoparticles to reinforce an asphalt mixture [15]. In another study, C. Li, Z. Fan, S. Wu, Y. Li, Y. Gan, and A. Zhang also evaluated the effects of carbon black nanoparticles from the pyrolysis of discarded tires on the performance of asphalt and its mixtures [11]. Yet another study presents the dispersion homogeneousness and performance enhancement of a carbon nanotubes (CNTs)-modified asphalt binder [7], authored by M. Haq, N. Ahmad, M. Nasir, Jamal; M. Hafeez, J. Rafi, S. Zaidi, and W. Haroon. In addition, the durability and the properties of an asphalt concrete with nano hydrophobic silane silica were evaluated considering the spring-thawing effect [5], in an article authored by W. Guo, X. Guo, M. Sun, and W. Dai.

Different types of waste oil have been utilized by investigators to improve virgin binder properties or rejuvenate aged binders. T. Shoukat and P. Yoo present a study on the rheology of an asphalt binder modified with 5w30-viscosity grade waste engine oil [16]. Meanwhile, J. Gao, H. Wang, Z. You, M. Mohd Hasan, Y. Lei, and M. Irfan used wood-derived bio-oil to modify an asphalt binder and evaluate its rheological behavior and sensitivity [5]. On the other hand, researchers investigated the possibility of using waste vegetable oil to rejuvenate aged asphalt binders [19]. Reclaimed asphalt pavement (RAP) is another hot research topic in recycling technology. In this Special Issue, two papers have been collected on this topic. The first one is an evaluation of the fatigue life of asphalt concrete mixtures with RAP [1], authored by W. Bańkowski. The second paper presents a method for evaluating the particle clustering phenomenon in RAP [20], authored by G. Xu, T. Ma, Z. Fang, X. Huang, and W. Zhang.

The mechanical properties of paving materials are always included within the scope of research interests. In this Special Issue, J.-C. Carret, H. Di Benedetto, and C. Sauzéat characterized asphalt mixes' behavior from dynamic tests and made a comparison with conventional cyclic tension-compression tests [2]. S. Lv, X. Fan, C. Xia, J. Zheng, D. Chen, and L. You characterized the moduli decay of an asphalt mixture under different loading conditions [14]; T. Huang, S. Qi, M. Yang, S. Lv, H. Liu, and J. Zheng presented a strength criterion of asphalt mixtures in three-dimensional stress states under freeze-thaw conditions [9]; X. Li, X. Lv, X. Liu, and J. Ye analyzed an indirect tensile fatigue test of an asphalt mixture using the discrete element method [12]; J. Chen, C. Yao, H. Wang, W. Huang, X. Ma, and J. Qian investigated the interface shear performance between a porous polyurethane mixture and asphalt sublayer [3]. Additionally, the deformation and damping of cement treated and expanded with polystyrene mixed lightweight subgrade fill were characterized under cyclic load [13], by W. Lu, L. Miao, J. Zhang, Y. Zhang, and J. Li.

Portland cement concrete is another widely used material for pavement construction. Two studies on this topic are included in this Special Issue. A case study in China was conducted by L. Yu, X. Yang, X. Yan, X. Zhang, T. Zhao, C. Duan, and J. Mills-Beale, presenting the design and construction of oblique prestressed concrete pavement [21]. M. Zheng, Y. Tian, X. Wang, and P. Peng investigated the durability of the anti-skid performance of grooved concrete pavement [25].

Pavement management and maintenance are essential for keeping transportation infrastructure in good service condition. Y. Tian, B. Ma, K. Tian, N. Li, and X. Zhou determined the components of light screening preventive maintenance agent (LS pre-maintenance agent) for strong ultraviolet (UV) radiation areas and evaluated its performance [17]. C. Kou, A. Kang, P. Xiao, P. Mikhailenko, H. Baaj, L. Sun, and Z. Wu presented a source pollution control measure based on the spatial-temporal distribution characteristic of the runoff pollutants at urban pavement sites [10].

Acknowledgments: This Special Issue would not be possible without the contributions of the above authors, hundreds of dedicated volunteer reviewers, and the editorial team of Applied Sciences.

Conflicts of Interest: The authors declare no conflict of interest. 


\section{References}

1. Bańkowski, W. Evaluation of Fatigue Life of Asphalt Concrete Mixtures with Reclaimed Asphalt Pavement. Appl. Sci. 2018, 8, 469. [CrossRef]

2. Carret, J.-C.; Di Benedetto, H.; Sauzéat, C. Characterization of Asphalt Mixes Behaviour from Dynamic Tests and Comparison with Conventional Cyclic Tension-Compression Tests. Appl. Sci. 2018, 8, 2117. [CrossRef]

3. Chen, J.; Yao, C.; Wang, H.; Huang, W.; Ma, X.; Qian, J. Interface Shear Performance between Porous Polyurethane Mixture and Asphalt Sublayer. Appl. Sci. 2018, 8, 623. [CrossRef]

4. Chen, P.; Chen, P.; Ye, N.; He, C.; Tang, L.; Li, S.; Sun, L.; Li, Y. Preparation of Polyacrylate Hollow Microspheres via Facile Spray Drying. Appl. Sci. 2019, 9, 228. [CrossRef]

5. Gao, J.; Wang, H.; You, Z.; Mohd Hasan, M.R.; Lei, Y.; Irfan, M. Rheological Behavior and Sensitivity of Wood-Derived Bio-Oil Modified Asphalt Binders. Appl. Sci. 2018, 8, 919. [CrossRef]

6. Guo, W.; Guo, X.; Sun, M.; Dai, W. Evaluation of the Durability and the Property of an Asphalt Concrete with Nano Hydrophobic Silane Silica in Spring-Thawing Season. Appl. Sci. 2018, 8, 1475. [CrossRef]

7. Ahmad, N.; Nasir, M.A.; Hafeez, M.; Rafi, J.; Zaidi, S.B.A.; Haroon, W. Carbon Nanotubes (CNTs) in Asphalt Binder: Homogeneous Dispersion and Performance Enhancement. Appl. Sci. 2018, 8, 2651.

8. Hasan, M.R.M.; You, Z.; Satar, M.K.I.M.; Warid, M.N.M.; Kamaruddin, N.H.M.; Ge, D.; Zhang, R. Effects of Titanate Coupling Agent on Engineering Properties of Asphalt Binders and Mixtures Incorporating LLDPE-CaCO 3 Pellet. Appl. Sci. 2018, 8, 1029. [CrossRef]

9. Huang, T.; Qi, S.; Yang, M.; Lv, S.; Liu, H.; Zheng, J. Strength Criterion of Asphalt Mixtures in Three-Dimensional Stress States under Freeze-Thaw Conditions. Appl. Sci. 2018, 8, 1302. [CrossRef]

10. Kou, C.; Kang, A.; Xiao, P.; Mikhailenko, P.; Baaj, H.; Sun, L.; Wu, Z. A Source Pollution Control Measure Based on Spatial-Temporal Distribution Characteristic of the Runoff Pollutants at Urban Pavement Sites. Appl. Sci. 2018, 8, 1802. [CrossRef]

11. Li, C.; Fan, Z.; Wu, S.; Li, Y.; Gan, Y.; Zhang, A. Effect of Carbon Black Nanoparticles from the Pyrolysis of Discarded Tires on the Performance of Asphalt and its Mixtures. Appl. Sci. 2018, 8, 624. [CrossRef]

12. Li, X.; Lv, X.; Liu, X.; Ye, J. Discrete Element Analysis of Indirect Tensile Fatigue Test of Asphalt Mixture. Appl. Sci. 2019, 9, 327. [CrossRef]

13. Lu, W.; Miao, L.; Zhang, J.; Zhang, Y.; Li, J. Characteristics of Deformation and Damping of Cement Treated and Expanded Polystyrene Mixed Lightweight Subgrade Fill under Cyclic Load. Appl. Sci. 2019, 9, 167. [CrossRef]

14. Lv, S.; Fan, X.; Xia, C.; Zheng, J.; Chen, D.; You, L. Characteristics of Moduli Decay for the Asphalt Mixture under Different Loading Conditions. Appl. Sci. 2018, 8, 840. [CrossRef]

15. Rafi, J.; Kamal, M.A.; Ahmad, N.; Hafeez, M.; Faizan ul Haq, M.; Aamara Asif, S.; Shabbir, F.; Bilal Ahmed Zaidi, S. Performance Evaluation of Carbon Black Nano-Particle Reinforced Asphalt Mixture. Appl. Sci. 2018, 8, 1114. [CrossRef]

16. Shoukat, T.; Yoo, P.J. Rheology of Asphalt Binder Modified with 5W30 Viscosity Grade Waste Engine Oil. Appl. Sci. 2018, 8, 1194. [CrossRef]

17. Tian, Y.; Ma, B.; Tian, K.; Li, N.; Zhou, X. Study on Components Determination and Performance Evaluation of LS Pre-Maintenance Agent. Appl. Sci. 2018, 8, 889. [CrossRef]

18. Wang, W.; Cheng, Y.; Ma, G.; Tan, G.; Sun, X.; Yang, S. Further Investigation on Damage Model of Eco-Friendly Basalt Fiber Modified Asphalt Mixture under Freeze-Thaw Cycles. Appl. Sci. 2019, 9, 60. [CrossRef]

19. Cao, X.; Cao, X.; Tang, B.; Wang, Y.; Li, X. Investigation on Possibility of Waste Vegetable Oil Rejuvenating Aged Asphalt. Appl. Sci. 2018, 8, 765.

20. Xu, G.; Ma, T.; Fang, Z.; Huang, X.; Zhang, W. The Evaluation Method of Particle Clustering Phenomena in RAP. Appl. Sci. 2019, 9, 424. [CrossRef]

21. Yu, L.; Yang, X.; Yan, X.; Zhang, X.; Zhao, T.; Duan, C.; Mills-Beale, J. Design and Construction of Oblique Prestressed Concrete Pavement: A Case Study in China. Appl. Sci. 2018, 8, 607. [CrossRef]

22. Zhang, C.; Wang, H.; You, Z.; Gao, J.; Irfan, M. Performance Test on Styrene-Butadiene-Styrene (SBS) Modified Asphalt Based on the Different Evaluation Methods. Appl. Sci. 2019, 9, 467. [CrossRef]

23. Zhang, W.; Ding, L.; Jia, Z. Design of SBS-Modified Bitumen Stabilizer Powder Based on the Vulcanization Mechanism. Appl. Sci. 2018, 8, 457. [CrossRef] 
24. Zhao, M.; Shen, F.; Ding, Q. Micromechanism of the Dispersion Behavior of Polymer-Modified Rejuvenators in Aged Asphalt Material. Appl. Sci. 2018, 8, 1591. [CrossRef]

25. Zheng, M.; Tian, Y.; Wang, X.; Peng, P. Research on Grooved Concrete Pavement Based on the Durability of Its Anti-Skid Performance. Appl. Sci. 2018, 8, 891. [CrossRef]

Publisher's Note: MDPI stays neutral with regard to jurisdictional claims in published maps and institutional affiliations.

(C) 2020 by the authors. Licensee MDPI, Basel, Switzerland. This article is an open access article distributed under the terms and conditions of the Creative Commons Attribution (CC BY) license (http://creativecommons.org/licenses/by/4.0/). 